\title{
Publisher Correction: Henceforth CRISPR
}

Correction to: Nature Biomedical Engineering https://doi.org/10.1038/s41551-020-00646-0, published online 15 October 2020.

In the version of this Editorial originally published, ref. 5 mistakenly read 'Young, J. et al. N. Engl. J. Med. 383, 1492-1494 (2020)'; it should have read 'Joung, J. et al. N. Engl. J. Med. 383, 1492-1494 (2020)'. This has now been corrected.

Published online: 27 October 2020

https://doi.org/10.1038/s41551-020-00651-3

( ) Springer Nature Limited 2020 